\title{
Os caminhos da inclusão das pessoas com deficiência: a evolução até a educação profissional e tecnológica da Rede Federal
}

\author{
The paths of inclusion of people with disabilities: the evolution through the professional and \\ technological education of the Federal Network
}

Los caminos de inclusión de personas con discapacidad: la evolución hacia la educación profesional y tecnológica en la Red Federal

\begin{abstract}
Resumo
O presente artigo tem por objetivo apresentar o percurso histórico da inclusão das pessoas com deficiência na educação enfatizando a educação profissional e tecnológica (EPT) na Rede Federal. Dessa forma, sob um olhar crítico, observou-se um caminho árduo, cheio de lutas e conquistas na inclusão das pessoas com deficiência na EPT. Os aspectos históricos percorrem o processo inicial de aceitação da pessoa com deficiência na sociedade até sua inserção na educação. A origem desse processo foi marcada por uma formação limitada mediante a deficiência, no entanto, é perceptível a evolução do processo educativo diante das pessoas com deficiência. Com as novas políticas de inclusão, como a criação dos Núcleos de Atendimento a Pessoas com Necessidades Educacionais Específicas (NAPNES), a Rede Federal possibilitou o acesso a tecnologias assistivas que promovem o ingresso, permanência e conclusão com êxito na sua formação tendo em vista sua inserção na sociedade e no mundo do trabalho.
\end{abstract}

Palavras-chave: Aspectos históricos; EPT; Formação profissional; NAPNE; Pessoa com deficiência.

\begin{abstract}
This article aims to present the historical path of inclusion of people with disabilities in education, emphasizing professional and technological education in the federal network. Thus, under a critical vision, a hard path was observed, full of struggles and achievements in the inclusion of people with disabilities in professional and technological training. Historical aspects go through the initial process of acceptance of people with disabilities in society until their insertion in education. The origin of this process was marked by limited training due to disability, however, the evolution of the educational process in the face of people with disabilities is noticeable. With new inclusion policies, such as the creation of service Centers for People with Specific Educational Needs (NAPNES), the federal network training enabled access to assistive Technologies that promote the entry, permanence and successful completion of their training taking into account considering its insertion in society and in the world of work.
\end{abstract}

Keywords: Historical aspects; EPT; Professional qualification; NAPNE; Disabled person.

\begin{abstract}
Resumen
Este artículo tiene como objetivo presentar el camino histórico de la inclusión de las personas con discapacidad en la educación, enfatizando la formación profesional y tecnológica en la Red Federal. Así, desde una perspectiva crítica, hubo un camino arduo, lleno de luchas y logros en la inclusión de personas con discapacidad en la formación profesional y tecnológica. Los aspectos históricos transcurren desde el proceso inicial de aceptación de la persona con discapacidad en la sociedad hasta su inserción en la educación. El origen de este proceso estuvo marcado por una formación limitada por discapacidad, sin embargo, se nota la evolución del proceso educativo frente a las personas con discapacidad. Con las nuevas políticas de inclusión, como la creación de Centros de Atención a Personas con Necesidades Educativas Específicas (NAPNES), la Red Federal posibilitó el acceso a tecnologías asistenciales que promuevan el ingreso, permanencia y culminación exitosa de su formación considerando su inserción en la sociedad y en el mundo laboral.
\end{abstract}

Palabras clave: Aspectos históricos; EPT; Formación professional; NAPNE; Persona discapacitada. 


\section{Introdução}

Ao longo da história percebemos grandes avanços no que concerne às políticas públicas de inclusão, principalmente após a promulgação de importantes documentos internacionais como a Declaração Mundial de Educação para Todos (1990) e a declaração de Salamanca (1994), que impulsionaram discussões sobre a inclusão das pessoas com deficiência na educação.

Em seguida, inúmeros outros documentos, resoluções e decretos, tanto nacionais como internacionais, ampliaram a participação dessas pessoas nos mais diversos setores da sociedade. Dentre eles, destaca-se a inserção das pessoas com deficiência no mercado de trabalho. No entanto, para que uma pessoa com deficiência possa exercer uma função com qualidade e encontrar-se habilitado à concorrer a uma vaga de emprego, faz-se necessário uma formação profissional.

A formação profissional no contexto dos Institutos Federais de Educação, Ciência e Tecnologia do Brasil, tem se colocado em lugar de destaque nas políticas públicas de inclusão. Os Institutos Federais surgiram trazendo uma política de inclusão que proporcionou aos seus inúmeros campi a organização dos Núcleos de Atendimento às Pessoas com Necessidades Educacionais Específicas (NAPNES), possibilitando ações que favorecem o acesso e permanência destes alunos.

Dessa forma, a inclusão das pessoas com deficiência na educação profissional e tecnológica é uma realidade nos dias atuais e isso se dá pelas inúmeras conquistas obtidas ao longo da história. Conhecer esse caminho é primordial para entendermos as relações estabelecidas no presente. Para tanto, será abordado o contexto histórico de lutas e conquistas por parte das pessoas com deficiência, tendo como destaque o direito à educação e seus aspectos legais, bem como, a história da inclusão dos alunos com deficiência nos Institutos Federais por meio da criação dos NAPNEs. Diante do contexto de formação profissional dos Institutos Federais, também será explanada a formação do educando para o mundo do trabalho numa perspectiva de trabalho como princípio educativo.

Este estudo tem como objetivo apresentar uma visão crítica sobre o percurso histórico da inclusão da pessoa com deficiência na educação, enfatizando a educação profissional e tecnológica na Rede Federal de Ensino.

\section{Metodologia}

O presente trabalho caracteriza-se como uma pesquisa do tipo exploratória, classificada segundo os procedimentos metodológicos como uma pesquisa bibliográfica e documental. Segundo Gil (2008), a pesquisa bibliográfica é indispensável em estudos históricos onde busca-se fontes secundárias de dados para elucidar fatos passados.

O texto aborda uma visão crítica da evolução da inclusão da pessoa com deficiência na educação profissional e tecnológica, por meio de um levantamento de informações e conhecimentos obtidos em documentos, livros e artigos científicos publicados em periódicos científicos. A coleta de dados foi realizada no período de agosto de 2019 a março de 2021, nas bases de dados Scielo, Periódicos Capes, Google Scholar, além de livros físicos e legislação advindas do Ministério da Educação e Cultura e do Planalto Federal. Os trabalhos foram selecionados por meio de uma leitura prévia avaliando a relevância dos aspectos históricos informados na publicação e a sua relação com o processo inclusivo das pessoas com deficiência e a EPT.

\section{Desenvolvimento}

\subsection{Aspectos históricos do processo inclusivo das pessoas com deficiência na educação}

A forma de perceber a deficiência é um reflexo de uma realidade histórica, política, social e econômica do homem. Nas comunidades primitivas as formas de produção eram a caça, pesca e a construção de abrigos, exigia-se do homem força física e habilidades específicas para sua sobrevivência. Nesse contexto, a pessoa com deficiência provavelmente, não teria seu espaço. Assim, subtende-se que eram eliminados nesse período (Jorge Neto \& Cavalcante, 2008). 
Segundo Fernandes (2013), é a partir da Antiguidade que aparece de forma mais clara registros da maneira como era tratada a pessoa com deficiência. No período greco-romano, o poder político e econômico da nobreza era baseado em laços hereditários e pela força de seus exércitos militares, o que favorecia na conquista de novas terras e escravos. As pessoas que tivessem deformidades físicas eram tidas como inúteis à sociedade e tinham como destino o abandono ou extermínio, pois configuravam em riscos e prejuízos. Somente na Idade Média, com o domínio da igreja e uma nova ordem econômica estabelecida como sociedade feudal, que esses extermínios foram condenados sobre a ideia de que essas pessoas eram criaturas de Deus. Os deficientes poderiam ter a sua participação na força de trabalho no contexto de que:

Os servos, a quem por direito apenas cabia a quarta parte da posse da terra para a produção e sustento, tinham a autonomia para decidir sobre o aproveitamento ou não da força de trabalho de pessoas com deficiências que viviam em sua gleba, já que os dogmas cristãos proibiam-lhes o extermínio (Fernandes, 2013, p. 40).

No entanto, ainda prevalecia uma concepção dúbia acerca das pessoas com deficiência. Por vezes, estas pessoas eram rotuladas como sendo possuídas pelo diabo, ou sob o domínio da feitiçaria, ou ainda, eram vistos como fruto do pecado dos pais, portanto, um castigo de Deus. Enquanto outros eram usados para entretenimento ou vistos de forma sobrenatural como detentores de poder (Piccolo \& Mendes, 2012).

No século XVI, foram criados os primeiros asilos e abrigos que davam assistência às pessoas com deficiência, com o objetivo de enclausurar essas pessoas, caracterizando um período da segregação das mesmas (Fernandes, 2017).

Essa fase da história da sociedade sofreu novas mudanças com a Revolução Burguesa. Nesse período, a medicina destacava-se ganhando status científico e contrapondo-se aos dogmas estabelecidos pela igreja, principalmente em relação à origem das deficiências, estabelecendo que estas tenham "causas naturais, e não mais por fatores espirituais" (Fernandes, 2017, p.43).

Nos séculos XVIII e XIX, as pessoas com deficiência eram integradas ao processo produtivo. Aqueles que não se encaixavam ao novo perfil de trabalhador eram destinados aos espaços de caráter filantrópico, assistencialista, educacional, ou incorporados novamente a uma prática de exibição de freak shows (Fernandes, 2017, p.45; Piccolo \& Mendes, 2012). Portanto, até a Revolução Industrial, eram nesses espaços de segregação que a educação às pessoas com deficiência era realizada, se destacando o modelo clínico terapêutico. A pedagogia estava subordinada a ciência médica, portanto, "a tarefa da educação especial seria a de desenvolver uma pedagogia terapêutica, com base em instrumentos e técnicas para descrever a deficiência e suas causas" (Fernandes, 2013, p. 55).

No período final do século XX, as políticas de inclusão começaram a influenciar o mundo e, gradativamente, aconteceram mudanças nas concepções de abordagem quanto a deficiência e o processo de atendimento educacional segregado, passando pelo processo de integração e depois de inclusão (Fernandes, 2013).

No Brasil, o atendimento às pessoas com deficiência teve início na época do império, em 1854, na cidade do Rio de Janeiro, com a criação do Imperial Instituto dos Meninos Cegos. Mais adiante, em 1891, pelo decreto $\mathrm{n}^{\circ} 1.320$, a escola passou a denominar-se Instituto Benjamin Constant (IBC). Em 1857, fundou-se o Imperial Instituto de Surdos-Mudos que, em 1957, pela lei no 3.198, passou a denominar-se Instituto Nacional de Educação de Surdos - INES (Mazzota, 2011).

Segundo Mazzota (2011), nesses institutos acontecia um atendimento voltado para a educação literária e profissionalizante. As oficinas oferecidas eram de tipografia, encadernação, tricô, sapataria, pautação e douração. No entanto, os alunos atendidos representavam uma irrisória parcela das pessoas com deficiência existentes no Brasil naquele período.

Ainda no segundo império, há registros de atendimento aos deficientes mentais voltado para um atendimento médicopedagógico. $\mathrm{O}$ atendimento às pessoas com deficiência na primeira metade do século $\mathrm{XX}$ cresceu através de estabelecimentos mantidos pelo poder público, bem como de instituições particulares. Dentre as instituições que se destacaram está o instituto 
Pestalozzi, criado em 1935, que tinha atendimento com caráter assistencial e educacional. Outro importante destaque está na fundação da Associação de Pais e Amigos dos Excepcionais (APAE), em 1954, no Rio de Janeiro (Mazzota, 2011).

Conforme Mazzota (2011), o governo federal assumiu pela primeira vez o atendimento educacional aos excepcionais de forma explícita a partir de campanhas voltadas para esse fim, tais como: Campanha para a Educação do Surdo Brasileiro (1957); Campanha Nacional de Educação e Reabilitação de Deficientes da Visão (1958); Campanha Nacional de Educação e Reabilitação de Deficientes Mentais (1960).

Posteriormente, com a aprovação da Lei $\mathrm{n}^{\circ} 5.692 / 71$, que em seu artigo $9^{\circ}$ previa "tratamento especial aos excepcionais", inúmeras ações foram desenvolvidas a fim de implantar novas diretrizes e bases para o ensino de $1^{\circ}$ e $2^{\circ}$ graus. Em 1973, ocorreu a criação do Centro Nacional de Educação Especial (CENESP) com o objetivo de promover em todo o território brasileiro a melhoria e a expansão do atendimento aos excepcionais com uma perspectiva integracionista. $\mathrm{O}$ CENESP, em 1986, sofreu mudanças transformando o órgão em Secretaria de Educação Especial - SESPE, o qual, em 1990, passou a ser a Secretaria Nacional de Educação Básica (SENEB). Por fim, no final de 1992, a Secretaria de Educação Especial (SEESP) reaparece (Jannuzzi, 2012).

Após esse período, surge a Coordenadoria Nacional para a Integração da Pessoa Portadora de Deficiência (CORDE), com objetivos mais amplos e trazendo alguma participação dos próprios deficientes. Em 1999, foi criado o Conselho Nacional da Pessoa com Deficiência (CONADE) com o objetivo de "acompanhar o planejamento e avaliar a execução de políticas setoriais de educação, saúde, assistência social, política urbana e outras relativas à pessoa portadora de deficiência" (Jannuzzi, 2012, p. 144).

Diante desse contexto histórico, percebe-se que a educação especial no Brasil ainda não estava pautada sobre uma política de inclusão eficiente. Mas, como em todo o processo histórico, paulatinamente as concepções foram amadurecendo e tomando formas diferenciadas como do início. Portanto, será enfatizado a seguir, dentro do contexto brasileiro, o avanço das políticas públicas de inclusão na educação em seus aspectos legais.

\subsection{Aspectos Legais no contexto brasileiro}

A primeira Lei de diretrizes e bases da educação Nacional, de $\mathrm{n}^{\circ} 4.024 / 61$, trouxe em seu dispositivo o direito dos “excepcionais” à educação, preferencialmente dentro do sistema geral de ensino. Segundo Mazzota (2012), a educação dentro dessa perspectiva abria a interpretação que, no momento em que essa educação dos excepcionais não encaixasse no sistema geral de ensino, ela poderia ser efetivada em um sistema especial de ensino, deixando a entender que essa educação ocorria à margem de uma educação central.

Em seguida, a Lei no 5.692/71, que altera a Lei de 1961, destaca o termo "tratamento especial" para os alunos com deficiências físicas, mentais, os que se encontram em atraso considerável quanto à idade regular de matrícula e os superdotados. Nesse período, essas leis não promoveram um ensino que de fato atendesse as especificidades educacionais desse público, os quais ainda eram encaminhados para classes e escolas especiais (Brasil, 2008).

Em 1988, a Constituição Federal constituiu um marco histórico quanto ao processo de inclusão das pessoas com deficiência no âmbito da educação. Nela, consta que a educação é direito de todos, não delimitando perfil de estudantes, independente de raça, condições econômicas, sexo ou mesmo deficiência. Além de garantir o atendimento educacional especializado preferencialmente na rede regular de ensino, oferecendo a esse aluno a escola regular como primeiro local para o seu desenvolvimento acadêmico e social.

No período de 1990-1994 importantes declarações internacionais passaram a influenciar a formulação de políticas públicas de educação inclusiva no Brasil. Dentre elas, a Declaração Mundial de Educação para todos (1990) e a Declaração de Salamanca (1994). Nesses documentos, são ressaltados os seguintes tópicos: a oportunidade educacional aos grupos excluídos 
da sociedade; a não discriminação; o reforço a educação inclusiva; e o respeito às individualidades das crianças em relação à aprendizagem.

Nesse mesmo período, foi publicada a Política Nacional de Educação Especial - PNEE (1994), trazendo as modalidades de educação especial. Dentre essas modalidades, destacou-se a classe comum, que foi caracterizada como um ambiente regular de aprendizagem em que os portadores de necessidades especiais, em caráter instrucional, poderiam estar matriculados, mas somente os que tivessem condições para acompanhar e desenvolver as atividades do ensino comum no mesmo ritmo dos alunos que não possuíssem deficiência (Brasil, 1994). Apesar da possibilidade dos alunos com deficiência ingressarem no ensino regular, a realidade não refletia uma política de inclusão preocupada em adaptar-se ao aluno, ao contrário, o aluno deveria ajustar-se ao ensino e não acontecendo isso, o mesmo era encaminhado à classe especial (Brasil, 2008).

Seguindo o percurso, em 1996, foi promulgada a atual Lei de Diretrizes e Bases da Educação Nacional, de n 9394/96, trazendo um capítulo destinado a Educação Especial, que inicialmente trouxe os termos "educandos portadores de necessidades especiais", e depois "educandos com necessidades especiais". Atualmente, em seu artigo 58, ao explicar a quem se trata a modalidade de educação especial oferecida de forma preferencial no sistema regular de ensino, define seu destino aos alunos com deficiência, transtornos globais do desenvolvimento, e altas habilidades e superdotação. Outro artigo que se destaca é o de número 59, inciso I, que assegura para esses estudantes, "currículos, métodos, técnicas, recursos educativos e organização específicos para atender às suas necessidades” (Brasil, 1996).

A partir de 1999, delinearam-se importantes diretrizes que instruíram as escolas para que elas se organizassem a fim de oferecer um atendimento especializado aos estudantes público alvo da educação especial, das quais: o Plano Nacional de Educação - PNE (2001); o decreto proveniente da Convenção da Guatemala (1999) ressaltando que "as pessoas com deficiência têm os mesmos direitos humanos e liberdades fundamentais que as demais pessoas..." (Brasil, 2008, p. 9); as resoluções que estabelecem diretrizes para a formação dos professores; portarias e outras leis que favorecem aos surdos e cegos (Brasil, 2008).

No período de 2003 a 2007 percebe-se a grande ênfase na inclusão; na formação de gestores; na escolarização do deficiente no ensino regular; ações que garantem a acessibilidade; a inclusão da Libras como disciplina do currículo; implantação dos Núcleos para pessoas com altas habilidades/superdotação; o lançamento do Plano Nacional de Educação em Direitos Humanos que propôs promover a discussão da temática relativas às pessoas com deficiência no currículo; também, nesse período, foi lançado o Plano de Desenvolvimento da Educação - PDE que estabeleceu "dentre as diretrizes do Compromisso Todos pela Educação, a garantia do acesso e permanência no ensino regular e o atendimento as necessidades educacionais especiais dos alunos...” (Brasil, 2008, p. 11).

A partir de então, as políticas de inclusão são fortemente estabelecidas e outras leis são criadas em prol da pessoa com deficiência, dentre elas, a Lei $n^{\circ}$ 12.764/2012 que institui a Política Nacional de Proteção dos Direitos da Pessoa com Transtorno do Espectro Autista; e a Lei no 13.146/2015 que institui a Lei Brasileira de Inclusão da Pessoa com Deficiência, conhecida como o Estatuto da Pessoa com Deficiência.

Em todos esses dispositivos legais, podemos perceber uma evolução quanto a Educação Especial e que, aos poucos, vem sendo colocada em evidência. Nas leis e documentos mais recentes trazem a garantia da educação das pessoas com deficiência em um ambiente cada vez mais inclusivo, em processos que proporcionem aos mesmos o desenvolvimento de suas potencialidades, respeitando suas diferenças e dando-lhes acesso a todos os níveis da educação. Entretanto, cabe ressaltar que mesmo esses direitos fixados em forma de lei não garantem que a realidade das pessoas com deficiência tome sobressaltos significativos quanto a sua efetiva participação na sociedade nos mais diversos setores, principalmente no ensino regular e no 
mundo do trabalho. É preciso que essas leis sejam reivindicadas na prática em um processo constante de luta da pessoa com deficiência.

\subsection{A inclusão da pessoa com deficiência na formação profissional no contexto da Rede Federal}

A educação das pessoas com deficiência não se delimitou apenas a formação básica, mas também, ampliou a sua formação para o mundo do trabalho. A pessoa com deficiência tem garantido por lei o direito de exercer a cidadania em todos os âmbitos da sociedade, e isso passa pela oportunidade de exercer suas funções produtivas. A Constituição Federal de 1988, em seu artigo 205, define que:

A educação, direito de todos e dever do Estado e da Família, será promovida e incentivada com a colaboração da sociedade, visando ao pleno desenvolvimento da pessoa, seu preparo para o exercício da cidadania e sua qualificação para o trabalho. (Brasil, 1988, p.123).

A educação profissional das pessoas com deficiência, principalmente de surdos, cegos e poucos deficientes intelectuais aconteciam em sua maioria em instituições filantrópicas, privadas e outras poucas ligadas ao poder público. Segundo Jannuzzi (2012), esse processo formativo se operacionalizava por meio de oficinas as quais treinavam os deficientes em tarefas específicas e repetitivas. Aquilo que era desenvolvido por eles não influenciava de forma rentável as empresas. As atividades consistiam em "separar pequenas peças, montar caixas, preencher envelopes com cartas, avisos etc. Não havia geralmente possibilidade de habilitação mais completa e específica” (Jannuzzi, 2012, p.151).

A Rede Federal de Educação Profissional, Científica e Tecnológica tem seu histórico marcado por uma política voltada a atender as classes desprovidas com a criação de 19 escolas de aprendizes e artífices pelo Presidente da República Nilo Peçanha em 1909. No entanto, a partir de 1980, o cenário econômico sofre grandes mudanças com o desenvolvimento de novas tecnologias somadas a produção e prestação de serviços. Diante do novo cenário, a Rede Federal amplia seus serviços em todo território brasileiro, qualificando profissionais nos diversos setores da economia (Ministério da Educação, 2021). A partir de 29 de dezembro de 2008, com a criação da Lei no 11.892, fica oficialmente instituída a Rede Federal de Educação Profissional, Científica e Tecnológica e cria os Institutos Federais de Educação, Ciência e Tecnologia (BRASIL, 2008).

A partir dos anos 2000, através do programa TEC NEP - Educação, Tecnologia e Profissionalização para as Pessoas com Necessidades Específicas nasceu a educação profissional e tecnológica inclusiva. O programa teve início a partir de uma pesquisa realizada nos institutos da rede federal que já tinham em seus currículos, cursos para pessoas com deficiência (Nascimento \& Faria, 2013).

Inicialmente, no período de 2000 a 2003, iniciou uma mobilização e sensibilização em toda a Rede Federal de Educação Profissional. Uma das ações realizadas foi uma Oficina de Trabalho com o tema: "PNE - Uma questão de inclusão". A mobilização e sensibilização tinham como objetivo a inclusão das pessoas com necessidades específicas no projeto políticopedagógico das Instituições e expandissem em suas sedes regionais a oportunidade da Educação Profissional para esse públicoalvo da Educação Especial (Nascimento \& Faria, 2013).

Depois, nos anos de 2003 a 2006, a ação TEC NEP, com o objetivo de descentralizar a gestão e a expansão de oferta às pessoas com necessidades específicas na educação profissional, divide a gestão em cinco polos regionais, facilitando uma implementação mais eficaz da ação de inclusão (Nascimento \& Faria, 2013).

Um dos pontos chaves dessa ação foi a implantação dos Núcleos de Atendimento às Pessoas com Necessidades Específicas (NAPNES) em âmbito interno das Instituições, com a finalidade de favorecer ainda mais as ações de inclusão dos alunos com deficiência, favorecendo o ingresso, a permanência e a conclusão com êxito de sua capacitação profissional (Cunha, 2015). O núcleo era composto por psicólogos, sociólogos, pais, estudantes, técnicos e docentes. Segundo Cunha 
(2015), os Napnes tinham por objetivo principal criar na instituição a cultura da "educação para a convivência". Essas ações tinham como objetivo a preparação das Instituições da Rede Federal de Educação Profissional, Científica e Tecnológica para expandir a oferta de educação às pessoas com necessidades específicas (Nascimento \& Faria, 2013, p.19-20).

Os anos de 2007 a 2009 consistiram no período para formação de pessoas para atuarem de forma efetiva com o público alvo da educação especial incluída na formação profissional, bem como, o incentivo ao uso de tecnologia assistiva (Nascimento \& Faria, 2013, 2013). Durante esse período, inúmeros projetos se destacaram por meio dos Napnes que se transformaram em ações práticas e desenvolvimento de instrumentos facilitadores, contribuindo para a permanência e conclusão dos cursos por parte das pessoas com deficiência.

É importante destacar que a formação profissional nos Institutos Federais possui um marco diferenciador em que o homem é visto como um ser integral e o trabalho como princípio educativo. A formação integral tem como intuito contribuir para a autonomia do sujeito nesse processo formativo, despertando no sujeito um olhar crítico e global no que se refere as mais variadas esferas sociais, inclusive no contexto do trabalho (Appio; Ewald \& Silva, 2020). Nesse sentindo, as pessoas com deficiência que adentram nos Institutos, são formadas em sua integralidade, afastando a visão fragmentada de homem.

Segundo Pacheco (2020), o trabalho como princípio educativo visa à superação da dicotomia entre trabalho intelectual e trabalho manual. De acordo com esse princípio a dimensão intelectual é incorporada ao trabalho produtivo. O conhecimento e o processo de ensino aprendizagem pensados dentro de um currículo integrador permite que "os conceitos sejam apreendidos como parte de um sistema de relação de uma totalidade concreta que se pretende explicar/compreender" (Pacheco, 2020, p.13).

Portanto, corroboramos com Carvalho \& Cavalcante (2020) quando apontam que as bases de formação dos Institutos Federais promovem de forma intencional a inclusão efetiva da Pessoa com Deficiência, proporcionando uma educação que o integra à sociedade com vistas a sua transformação.

\section{Considerações Finais}

A história mostra que as pessoas com deficiências tiveram que percorrer um longo caminho para que pudessem gozar de leis que lhe assegurassem a inclusão em diversos espaços na sociedade, principalmente em relação à profissionalização e sua inserção no mercado de trabalho. No entanto, a formação profissional da pessoa com deficiência e sua inclusão dentro dessa realidade do trabalho, segue como componente desafiador das políticas públicas de inclusão e, por isso, entende-se ser importante que a temática aqui abordada continue sendo pesquisada.

Ressalta-se de forma positiva a formação profissional realizada dentro dos Institutos Federais do Brasil aos estudantes com deficiência, cuja formação tem seus alicerces firmados em uma sólida política pública de inclusão, além dos princípios dos quais são baseados seu currículo, no que diz respeito a formação de um homem integral com base no trabalho como princípio educativo.

Para finalizar, sugere-se ser de suma importância a investigação de ações de inclusão que estão contribuindo para a formação profissional da pessoa com deficiência no contexto dos Institutos Federais do Brasil, a fim de trazer ao público a relevância de práticas inclusivas para que sirvam de inspiração para outras instituições que se propõem a capacitar profissionalmente estudantes com deficiência. Além disso, que dessas pesquisas se construam produtos educacionais que favoreçam a inclusão, permanência e conclusão com êxito da formação das pessoas com deficiência.

\section{Referências}

Appio, C., Ewald, I. \& Silva, V. (2020) A formação integral na educação profissional tecnológica: Alguns apontamentos. Metodologias e Aprendizado, 1, 1116. <https://doi.org/10.21166/metapre.v1i0.1100>

Brasil. (1957). Decreto n 42.728 , de 3 de dezembro de 1957. Institui a Campanha para a Educação do Surdo Brasileiro. Portal da Câmara dos Deputados. https://www2.camara.leg.br/legin/fed/decret/1950-1959/decreto-42728-3-dezembro-1957-381323-publicacaooriginal-1-pe.html. 
Brasil. (1958). Decreto n ${ }^{\circ} 44.236$, de 1 de agosto de 1958. Institui a Campanha Nacional de Educação e Reabilitação dos Deficitários Visuais. Portal da Câmara dos Deputados. https://www2.camara.leg.br/legin/fed/decret/1950-1959/decreto-44236-1-agosto-1958-383373-publicacaooriginal-1-pe.html.

Brasil. (1960). Decreto no 48.96, 1 de 22 de setembro de 1960. Institui a Campanha Nacional de Educação e Reabilitação de Deficientes Mentais. Portal da Câmara dos Deputados. https://www2.camara.leg.br/legin/fed/decret/1960-1969/decreto-48961-22-setembro-1960-388634-publicacaooriginal-1-pe.html.

Brasil. (1961). Lei 4.024, de 20 de dezembro de 1961. Fixa as Diretrizes e Bases da Educação Nacional. Portal da Câmara dos Deputados. https://www2.camara.leg.br/legin/fed/lei/1960-1969/lei-4024-20-dezembro-1961-353722-publicacaooriginal-1-pl.html.

Brasil. (1971). Lei 5.692, de 11 de agosto de 1971. Fixa Diretrizes e Bases para o ensino de $1^{\circ}$ e $2^{\circ}$ graus, e dá outras providências. Portal da Câmara dos Deputados. https://www2.camara.leg.br/legin/fed/lei/1970-1979/lei-5692-11-agosto-1971-357752-publicacaooriginal-1-pl.html.

Brasil. (1973). Decreto n ${ }^{\circ} 72.425$, de 3 de julho de 1973. Cria o Centro Nacional de Educacional Especial (CENESP), e dá outras providências. Portal da Câmara dos Deputados. https://www2.camara.leg.br/legin/fed/decret/1970-1979/decreto-72425-3-julho-1973-420888-publicacaooriginal-1-pe.html.

Brasil. (1990). Lei n. 8.069, de 13 de julho de 1990. Estatuto da Criança e Adolescente no Brasil. Portal da Câmara dos Deputados. https://www2.camara.leg.br/legin/fed/lei/1990/lei-8069-13-julho-1990-372211-publicacaooriginal-1-pl.html.

Brasil. (1991). Lei n. 8.213, de 24 de julho de 1991. Planos de Benefícios da Previdência Social. Portal da Legislação. http://www.planalto.gov.br/ccivil_03/leis/18213cons.htm.

Brasil. (1996). LDB 9.394, de 20 de dezembro de 1996. Lei de Diretrizes e Bases da Educação Nacional. Portal da Legislação. http://www.planalto.gov.br/ccivil_03/leis/19394.htm.

Brasil. (1988). Constituição: República Federativa do Brasil. https://www2.senado.leg.br/bdsf/bitstream/handle/id/518231/CF88_Livro_EC91_2016.pdf

Brasil. (2000). Lei n. 10.098, de 19 de dezembro de 2000. Estabelece normas gerais e critérios básicos para a promoção da acessibilidade das pessoas portadoras de deficiência ou com mobilidade reduzida, e dá outras providências. Portal da Legislação. http://www.planalto.gov.br/ccivil_03/leis/110098.htm.

Brasil. (2001). Lei n. 10.172, de 09 de janeiro de 2001. Plano Nacional de Educação. Portal da Legislação. http://www.planalto.gov.br/ccivil_03/leis/leis_2001/110172.htm.

Brasil. (2008). Ministério da Educação. Política Nacional da Educação Especial na Perspectiva da Educação Inclusiva, 2008. Portal do MEC. http://portal.mec.gove.br/arquivos/pdf/politicaeducespecial.pdf.

Brasil. (2012). Lei n. 12.764, de 27 de dezembro de 2012. Política Nacional de Proteção dos Direitos da Pessoa com Transtorno do Espectro Autista. Portal da Legislação.http://www.planalto.gov.br/ccivil_03/_Ato2011-2014/2012/Lei/L12764.htm.

Brasil. (2015). Lei n. 13.146, de 6 de julho de 2015. Lei Brasileira de Inclusão da Pessoa com Deficiência. Portal da Legislação. http://www.planalto.gov.br/ccivil_03/_ato2015-2018/2015/lei/113146.htm.

Carvalho, E. Q., \& Cavalcanti, R. J. de S. (2020). Inclusão na Educação Profissional e Tecnológica: abordagem emancipatória do trabalho como princípio educativo. Research, Society and Development, 9(5), e115953219. https://doi.org/10.33448/rsd-v9i5.3219.

Cunha, A. L. B. M. (2015). O programa TEC NEP e sua implementação na rede federal de educação profissional, científica e tecnológica: ressonâncias acadêmicas, limites e desafios. [dissertação de mestrado, Instituto Federal de Educação, Ciência e Tecnologia do Rio Grande do Norte]. Memória, repositório institucional. http://memoria.ifrn.edu.br/handle/1044/761.

Declaração de Salamanca. (2019). Sobre os princípios, políticas e práticas na área das necessidades educativas especiais. Portal do MEC. http://portal.mec.gov.br/seesp/arquivos/pdf/salamanca.pdf.

Declaração mundial sobre Educação para Todos. (1990). Plano de ação para satisfazer as necessidades básicas de aprendizagem. https://www.unicef.org/brazil/declaracao-mundial-sobre-educacao-para-todos-conferencia-de-jomtien-1990.

Fernandes, S. (2013). Fundamentos pra educação especial. InterSaberes.

Gil, A. C. (2008). Métodos e técnicas de pesquisa social. (6a.ed.). Atlas.

Jannuzzi, G. S. M. (2012). A educação deficiente no Brasil: dos primórdios ao início do século XXI. (3ª.ed.). Autores Associados.

Jorge Neto, F. F. \& Cavalcante, J. Q. P. (2008). Direito do trabalho. (4a.ed.). Lumen Juris.

Mazzota, M. J. S. (2011). Educação Especial no Brasil: história e políticas públicas. (6a.ed.). Cortez.

Ministério da Educação. (2021). Rede Federal de Educação Profissional Científica e Tecnológica. http://portal.mec.gov.br/rede-federal-inicial.

Nascimento, F \& Faria, R. (2013). A questão da Inclusão na Rede Federal de Educação Profissional, Científica e Tecnológica, a partir da ação TEC NEP. In F.C. Nascimento, G.M.F. Florindo, \& N.S. Silva (Orgs.), Educação Profissional e tecnológica Inclusiva: um caminho em construção (pp.13-23). IFB. https://doi.org/10.19123/edifb.v0i0.185.

Pacheco, E. (2020). Desvendando os institutos federais: Identidade e objetivos. Educação Profissional e Tecnológica em Revista, 4(1), 4-22. https://doi.org/10.36524/profept.v4i1.575.

Piccolo, G. M., \& Mendes, E. G. (2012). Nas pegadas da história: tracejando relações entre deficiência e sociedade. Revista Educação Especial, 25(42), 29-42. https://doi.org/10.5902/1984686X4611. 
Research, Society and Development, v. 10, n. 12, e504101220702, 2021

(CC BY 4.0) | ISSN 2525-3409 | DOI: http://dx.doi.org/10.33448/rsd-v10i12.20702

Silva, P. N, Prais, F. G \& Silveira, A. M. (2015). Inclusão da pessoa com eficiência no mercado de trabalho em Belo Horizonte, Brasil: cenário e perspectiva. Ciência e Saúde Coletiva, 20(8), 2549-2558. https://doi.org/10.1590/1413-81232015208.17802014.

Tanaka, E. D. O \& Manzini, E, J. (2005). O que os empregadores pensam sobre o trabalho da pessoa com deficiência? Revista Brasileira de Educação Especial, 11(2), 273-294. https://doi.org/10.1590/S1413-65382005000200008. 